América sin Nombre, n. ${ }^{\circ} 21$ (2016): 11-20

DOI: 10.14198/AMESN.2016.21.12

ISSN: 1577.3442 / eISSN: 1989-9831
Puede citar este artículo como:

Zugasti, Miguel. «“... con sus loas, sainetes y entremeses”. Reivindicación del teatro breve virreinal». Teatro breve virreinal. Miguel Zugasti (coordinador). América sin Nombre, 21 (2016): 11-20, DOI: 10.14198/AMESN.2016.21.12

Link para este artículo: http://dx.doi.org/10.14198/AMESN.2016.21.12

\title{
«... con sus loas, sainetes y entremeses». Reivindicación del teatro breve virreinal*
}

\author{
«... con sus loas, sainetes y entremeses». \\ A defense of the short Viceroyal theatre
}

Miguel Zugasti

Universidad de Navarra

Aún está por escribir una historia del arte escénico desplegado en los virreinatos americanos (y en la Capitanía General de Filipinas) durante los siglos de presencia española en aquellos dilatados territorios, en un periodo que -con las lógicas oscilaciones de fechas según iban alcanzando la independencia unos países y otros- a grandes rasgos discurre desde el siglo Xvi hasta el XIX. Hablamos de una historia integral y comprensiva del teatro, que abarque aspectos tan variados como los mecanismos de producción y exhibición de las obras, el público asistente y sus preferencias, los espacios de representación (corrales, coliseos, plazas, conventos, palacios, cementerios...), la pervivencia y rescate de los textos, la adscripción genérica de dichos textos, los repertorios conservados, la diversidad idiomática (castellano, latín -muy utilizado en el teatro universitario y de colegio-, náhuatl, otomí, quechua, tagalo...), las complejas relaciones establecidas entre dramaturgos, autores y actores, la presión ejercida por censores e inquisidores, la fusión del arte dramático con otras artes hermanas como la danza, el canto y la música, etc., etc. Son muchos frentes a tener en cuenta, pues sabemos bien que el teatro trasciende el texto escrito y lo revitaliza sobre las tablas (oralidad, dramaticidad), así

\footnotetext{
* Este trabajo se integra en el proyecto de investigación Teatro, fiesta y ritual en la monarquía hispánica (ss. XVI-XVII), financiado por la Subdirección General de Proyectos de Investigación: MINECO, referencia: FFI2013-48644-P.
}

que solo participa de la literatura y su historiografía de modo parcial. Atender a estos frentes y estudiarlos uno a uno o en su conjunto, repito, resultaría de gran ayuda para cartografiar mejor la prolija actividad teatral desarrollada en los virreinatos.

A los primigenios manuales de literatura hispanoamericana (Lazo, Anderson Imbert, Bellini...) donde el teatro recibía una atención más bien escasa, les complementan nuevas aproximaciones que inciden con mayor énfasis en la praxis escénica: Trenti Rocamora, Arrom, Suárez Radillo, Shelly y Rojo, Goic, García Valdés y Prieto, Oviedo, González Echevarría y Pupo-Walker, etc. Son visiones de conjunto susceptibles de enriquecerse con los aportes particulares provenientes de unos países y otros, de modo que sumándolo todo podremos delinear mejor un panorama global del teatro en los territorios del ultramar hispánico. Por razones históricas, los virreinatos de Nueva España y el Perú son los mejor estudiados (Olavarría y Ferrari, Schilling, María y Campos, Argudín, Peña o Poot Herrera en México; Lohmann Villena, Tamayo Vargas o Balta en el Perú), pero también se han hecho rebuscas especializadas en otras zonas geográficas como Colombia-Nueva Granada (Orjuela, Reyes Posada), Bolivia-Charcas (Gisbert, Eichmann), Chile (Amunátegui, Cánepa Guzmán, Pereira Salas), Argentina (Marsili, Ordaz, Pellettieri), Uruguay (Rela), Paraguay (Plá), Venezuela (Arrom), Guatemala (Díaz Vasconcelos), El Salvador (Velis), Cuba (Tolón y González) o Filipinas (Retana), entre 
otros. Especial interés crítico ha merecido el teatro evangelizador que los misioneros españoles trasplantaron al Nuevo Mundo con fines catequéticos y doctrinales (Arróniz, Betancourt, Partida, Williams, Aracil Varón, Sten, Schuessler).

Si observamos con calma este panorama bibliográfico -el cual, por otra parte, no va más allá de un simple esbozo-, pronto detectamos un cierto vacío que se cierne sobre el conjunto: son muchas las noticias recopiladas por doquier de representaciones, estrenos y festejos teatrales, pero son bastantes menos los textos que han sobrevivido al paso de los siglos, y el número de estos últimos decrece exponencialmente a la hora de su disponibilidad en ediciones fiables y de garantías. Por ende, si esto pasa con el teatro largo (comedias, autos...), el problema se agudiza con el teatro breve, donde la nómina de títulos al alcance del lector y/o espectador contemporáneo se adelgaza todavía más. Autores de gran prestigio como Sor Juana Inés de la Cruz, Ruiz de Alarcón o Fernán González de Eslava cuentan con más de una edición solvente de sus obras completas, pero eso es la excepción y no la norma. En una situación mucho más precaria se hallan dramaturgos como Lorenzo de las Llamosas, Peralta Barnuevo, Francisco del Castillo, Fernando de Orbea, Eusebio Vela..., cuyos textos se publicaron en el siglo Xx sin las debidas consideraciones críticas. Más fortuna han tenido Cabrera y Quintero, Pedro de Morales, Juan de Cigorondo, Matías de Bocanegra, Espinosa Medrano o Diego de Ocaña, cuidadosamente editados por Parodi, Mariscal Hay, Alonso Asenjo (2002, 2006, 2012) y Arteaga Martínez, Sainz Bariáin, Vitulli y Peña Núnez. En el caso de México ha marcado un hito, por su alcance y divulgación, la dilatada serie de "Teatro mexicano. Historia y dramaturgia», impulsada por el Consejo Nacional para la Cultura y las Artes (CONACULTA), coordinada por Héctor Azar, con el concurso de los más reputados especialistas (a nuestros efectos interesan sobre todo los diez primeros volúmenes). En esa misma línea, Ricardo Silva-Santisteban ha elaborado una Antología general del teatro peruano (2000), con especial atención al teatro colonial de los siglos XVI-XVII (vol. 2) y XviII (vol. 3). Sin salirnos del Perú, urge ya una reedición del libro de Rubén Vargas Ugarte, De nuestro antiguo teatro. Colección de piezas dramáticas de los siglos XVI, XVII y XVIII (1943; 1974), habida cuenta de que hace muchos años que está fuera del mercado y de que algunos de los textos ahí publicados son testimonios únicos, pues sus originales desaparecieron en un calamitoso incendio de la
Biblioteca Nacional de Lima. Con especial atención a la Nueva España de los siglos Xvi y XviII, hay que aplaudir los respectivos empeños editores de Rojas Garcidueñas y Germán Viveros, quienes en su dilatada trayectoria han sacado a luz numerosos textos. Cerramos este breve apunte con el reciente hallazgo de una comedia desconocida e inédita como es $E l$ esposo por enigma, ejecutada en México en 1646 y rescatada del olvido por Emilio de Miguel y Javier San José (2006).

Este pequeño bosque de nombres de dramaturgos se clarea bastante cuando dirigimos nuestra mirada hacia el teatro breve virreinal, tanto en su vertiente cómica -la principal- como seria. Ya sea por su reducida extensión, ya sea por su consideración de 'teatro menor' o de simples 'juguetes' que suelen ir adheridos a las piezas largas (de ahí las reiteradas noticias de representación de comedias «con sus loas, sainetes y entremeses»), el caso es que se trata de un territorio abonado a la anonimia y la desatención crítica. A la altura de 1786, el Coliseo de México disponía entre sus fondos de más de 200 comedias, bien acompańadas por 160 sainetes y 80 entremeses (Viveros 1992, 172); un cuarto de siglo después, al hacer un inventario de la «oficina de comedias» del Coliseo de Puebla de los Ángeles (1801), se localizaron los libretos de « 25 comedias inservibles, 60 sainetes y follas inservibles [y] 23 comedias impresas maltratadas» (Gómez Haro 45). Se entrevé que el número de textos teatrales breves exhibidos en los escenarios virreinales (importados de la metrópoli o escritos ad hoc en América) fue muy superior al de las comedias, zarzuelas, autos u otras piezas largas. Sin embargo, la paradoja surge cuando, de un lado, observamos que apenas identificamos a un puñado de dramaturgos que cultivaron los géneros breves, $\mathrm{y}$, de otro lado, cuando se constata la triste realidad de que muy pocos de sus títulos han sido publicados modernamente, excepción hecha de los creados por figuras descollantes como Sor Juana Inés de la Cruz (firmó 18 loas, 2 sainetes y un sarao) o González de Eslava (autor de 16 coloquios, 10 loas y/o argumentos, más 4 entremeses).

Sin lugar a dudas, el género rey del teatro breve fue la loa, en toda su amplia variedad: loas que anteceden a comedias, loas genetlíacas o de cumpleaños, loas de carro triunfal, loas de arco para las entradas de virreyes, obispos, arzobispos, militares de alto rango..., loas sacramentales, loas palaciegas, etc. Muchas veces, en contra de lo que se cree, tales loas no se limitaban a introducir un espectáculo mayor, sino que ellas mismas ocupaban el centro del 
festejo teatral, sin más aditamentos: Festivo aparato a San Francisco de Borja (México, 1672); Antonio Navarrete, Relación peregrina de la agua (Querétaro, 1738). Hay innumerables relaciones de festejos que certifican la presencia de loas y/o encomios, pero no siempre se transcriben sus versos; dicho lo cual, aún permanecen docenas de loas aletargadas y olvidadas por la crítica en el seno de tales libros de fiestas. Se podría decir que casi no hay virrey u obispo al que no se le 'eche' la loa cuando toma posesión de su cargo o-simplemente- visita una ciudad importante. En el caso de la Nueva España era usual que, al entrar en la Ciudad de México el virrey recién nombrado, los cabildos civil y catedralicio erigieran sendos arcos triunfales donde se declamaban las respectivas loas. Pero no solo en la capital, pues en el itinerario previo que discurría desde Veracruz hasta México podía acontecer otro tanto. Disponemos de un testimonio excepcional como es el Viaje de tierra y mar, feliz por mar y tierra, que hizo el excellentísimo señor Marqués de Villena (México, 1640), escrito por Cristóbal Gutiérrez de Medina, donde se afirma que este virrey fue obsequiado con loas dramáticas en Tlaxcala y Puebla. En resumen: el Viaje de tierra y mar habla de cuatro loas y recopila dos de ellas, las cuales - hasta donde conozco- no han sido reeditadas por la crítica (Zugasti, 2014a). Es un simple ejemplo de los muchos que podríamos aducir y que omitimos para evitar cansinas reiteraciones, pues el proceso se repite en Perú, Chile, Guatemala, Filipinas y otros lugares.

Hay muchas más fuentes ricas en información, como es el caso de los papeles confiscados al caballero italiano Lorenzo Boturini, de los cuales se hizo inventario cuando él estaba preso en México (27 de septiembre de 1743). Así, entre las distintas obras de tema guadalupano que poseía, se hallaba «un coloquio y su entremés en honra y memoria de la Santísima Cruz, en dicho papel y lengua mexicana, que se compuso en ocasión de las fiestas que hacen los indios a dicha Santa Cruz» (Peñafiel III, 65, ítem 34); prosiguiendo dicho inventario al día siguiente, consta que se le requisó también un ejemplar de la «Loa que se recitó en el monte de Guadalupe, en tiempo que se erigió una Ermita en él; impresa, su autor el Br. Antonio de Medina Soliz, en octavo» (Peñafiel III, 66, ítem 20). Otra vía de acceso es la nutrida Reseña histórica del teatro en México, de Olavarría y Ferrari (manejo edición moderna de México: Porrúa, 1961). Este crítico poseyó una colección manuscrita "de loas y entremeses, y de comedias de santos y pastorelas, que una casualidad trajo a mis manos. Esa casualidad no producirá, desgraciadamente, honra grande a las letras patrias, y quizá hubiérase perdido poco no sacando a luz la colección; tan pobre así es el hallazgo; pero supla a lo bueno lo curioso" (I, 88). Desconozco el paradero de dicha colección, aunque a pesar de tan severo juicio no hay duda de que hoy la veríamos con otros ojos. Por suerte, la curiosidad de Olavarría y Ferrari le impelió a publicar alguno de esos textos, siquiera fragmentariamente: Loa en obsequio de la Purísima (I, 88-91), Entremés para las Posadas (I, 91-94), Loa en obsequio de nuestra Señora de Guadalupe (I, 94-105), parte de una loa donde aparecen la Culpa y la Gracia (I, 108-110), parte de un sainete titulado El indio criado (I, 111) y parte de un coloquio o pastorela (I, 112-124).

Caso singular es el de fray Juan de la Anunciación, autor de un manuscrito titulado Cuaderno de varios versos, y que en sus 233 folios copia múltiples poesías religiosas y profanas (Ihmoff Cabrera, 1985), varios coloquios (Germán Viveros, 1996) y unas ochenta y dos loas, la mayoría de ellas aún inéditas. Otra figura que urge recuperar del olvido es la del mestizo Joseph Antonio Pérez de la Fuente, autor de un conjunto de loas, encomios, jácaras... que presentan la particularidad de haber sido escritos en náhuatl, mezclado a veces con pasajes en español, según se ve en las acotaciones escénicas o en los parlamentos declamados por personajes de origen español que se sirven de su lengua materna ${ }^{1}$. Mutatis mutandis, el panorama aquí dibujado de la loa en México se repite con pocas variantes en otras zonas, donde son bienvenidos los estudios de conjunto como los que Correa y Cannon dedican a la loa en Guatemala, Irving a la de Filipinas, o la reedición de textos de difícil acceso que conviene actualizar: Parodi recuperó el teatro breve de Cabrera y Quintero; Pascual Buxó hizo lo propio con dos loas de fray Lorenzo del Santísimo Sacramento; Zugasti rescata dos loas escritas en Potosí (2005, 181-187; 2008), además de otras dos ofrecidas al virrey Monclova en Puebla de los Ángeles y Lima (2014b); Prendes Guardiola saca a luz otra loa declamada en Piura (2013), y Sancho Dobles edita una loa y dos entremeses del costarricense Joaquín de Oreamuno (2016).

Dejando la loa atrás, otras piezas cortas y de extensión variable no citadas hasta ahora son los coloquios,

1. Para el teatro en náhuatl remito a los dos volúmenes preparados por Horcasitas, aunque no menciona a Pérez de la Fuente, autor del que me ocuparé en un futuro trabajo. 
diálogos, encomios, églogas, pastorelas, decurias... que tienden a transitar por la senda de lo serio. Si saltamos al teatro cómico breve observamos que es igualmente dúctil en sus formas, pues incluye entremeses, sainetes, saraos, fines de fiesta, pasos, jácaras, juegos, vejámenes, bailes, danzas, mojigangas... A pesar de tanta variedad, insistimos, es relativamente bajo el número textos de este tenor que ha llegado hasta nosotros. Y ello a veces por cauces sorprendentes, como es el caso de cierto entremés escrito por Cristóbal de Llerena y ejecutado en el atrio de la catedral de Santo Domingo por unos estudiantes el 23 de junio de 1588, en la octava del Corpus Christi. La obra, que supuestamente satirizaba a las instituciones virreinales, causó un revuelo tan grande que quince días después su autor fue enviado a Riohacha, Nueva Granada (actual Colombia). Además, Llerena fue denunciado a la Inquisición, la cual lo declaró inocente un año después y lo rehabilitó en sus oficios. El texto se ha conservado merced a dicho proceso inquisitorial, de donde lo recogió Francisco A. de Icaza en 1921 en el Archivo de Indias (Molinaza, 39-44). Lo mismo cabe decir de otras piezas conservadas en el Archivo General de la Nación de la Ciudad de México (ramo Inquisición), como son el Entremés del galán liberal (el texto parece provenir de Manila), una Mojiganga de los frailes y otra Mojiganga dedicada a Carlos IV y su estatua (los edita Viveros 1996, 101-186 y 203-228), o de cierto Entremés de Luisa incautado por el Santo Oficio en Zacatecas (Jiménez Rueda, Camastra) ${ }^{2}$. Este teatro cómico breve también supo hacerse un hueco en los conventos de monjas, según lo demuestran las recopilaciones de Arellano y Eichmann (2005) y Sten y Gutiérrez Estupiñán (2007). Contamos con algunos aportes más de dramaturgos de cierto fuste como Peralta Barnuevo (dos bailes, dos fines de fiesta, una loa y un entremés), Lorenzo de las Llamosas (un sainete y un baile editados por Zugasti, 1999), Juan del Valle y Caviedes (tres bailes: 1990, 753-766) y Francisco del Castillo,

2. Por idéntico conducto ha llegado hasta nosotros El pregonero de Dios y patriarca de los pobres, comedia de Francisco de Acevedo sobre el santo de Asís que fue retenida por la Inquisición en 1684, y publicada por Jiménez Rueda en 1945. Otras veces, claro está, hay noticias de obras censuradas o secuestradas por la Inquisición, cuyos textos no han sobrevivido: tal el caso del Entremés alegórico del entremetido, la dueña y el soplón, prohibido -según el censor- por estar lleno de «detracciones, improperios, irrisiones, dicterios e injurias a personas conocidas de calidad y letras y estado de religiosos» (Ortiz Bullé Goyri 136). el Ciego de la Merced (tres loas, dos entremeses, un sainete y un fin de fiesta: 1996), pero en general ya solo podemos ańadir títulos sueltos: Laurea crítica (de Fernández de Valenzuela), Baile de Diablos (Correa), El amor duende (sainete de Monforte y Vera), Sarao de los planetas (de Jerónimo Fernández de Castro). En las últimas décadas del siglo XviII surge con fuerza la modalidad del sainete criollo de corte costumbrista, que seguirá activo durante la centuria siguiente $-\mathrm{y}$ penetra incluso en el siglo $\mathrm{xx}$ - en Argentina, México y otros países: algunos ejemplos tempranos son El amor de la estanciera (anónimo, al estilo gauchesco), El charro y Los remendones (de José Agustín de Castro). Tres de estos entremeses populares novohispanos de fines del siglo XviII fueron publicados por Jiménez Rueda (1944): El mulato celoso, de Macedonio Espinosa (331-340), El alcalde Chamorro (341-352) y el Entremés de las cortesías, de Manuel Borla (353-362); además, la Biblioteca del Instituto Nacional de Antropología e Historia (INAH) custodia muchos de ellos manuscritos e inéditos (procedentes de conventos como el de Santa Mónica de Puebla, el Colegio de San Gregorio y la catedral de Puebla), donde aparecen títulos como el Entremés de las albóndigas y el Sainete jocoso entre un indio y una india (Viveros 1996, 265-273), Sainete Noche Triste, Entremés la cena de Noche Buena, Entremés de los guajolotes que se pelearon, Entremés la Archiduquesa de Irlanda (Sten y Gutiérrez Estupiñán 19-20), Los indios cantores, El casamiento de los indios, La sombra, El tamborcito, El poeta (Ortiz Bullé Goyri 138-139), Los payos y el cazador, La mexicana astrónoma, El tuno borracho, Las mañas de una casada, La malicia popular... (Viveros 1990, XXXV y XL)3. Aquí se repite la pauta de que son muy pocos los textos conservados, frente al aluvión de títulos existentes, muchos de los cuales registra también con puntualidad Olavarría y Ferrari (I, 28-29; 127-130; 158-159). Cito unos pocos, que casi con seguridad serán los mismos que se hallaban al por mayor en los citados coliseos de México y Puebla allá por los ańos de 1786 y 1801: La máscara, El abate hablador, El arcabuceado, Los payos simples, El payo y la novia, La besuguera, Las majas celosas, El medio simple, La procesión, El oso, La venta, El soldado fanfarrón, Los bandos del Avapiés, El celoso confundido, La maja majada, El negro sensible y un largo etcétera de bailes, follas, tonadillas y demás variantes del género breve, convenientemente 3. Disponemos asimismo de una antología más moderna de
sainetes argentinos al cuidado de Tulio Carella (1957). 
mezclados los de producción autóctona con los procedentes de la Península Ibérica, firmados sobre todo por Ramón de la Cruz (Los bandos del Avapiés, La maja majada...). Añadiré por último que la Bancroft Library de la University of California Berkeley custodia un códice (Ms. 2015/153) que contiene estas dieciséis piezas breves: 1. Pastorela; 2. Entremés de los locos; 3. Entremés de los remendones; 4. Entremés de la junta de médicos; 5. Sainete nuevo intitulado Fuera; 6. Entremés del payo; 7. Entremés del visconde caballero despojado; 8. Entremés del droguero; 9. Entremés de la lenterna o de la selosa burlada; 10. Entremés del gallego; 11. Entremés del fingido minero o Nana Eufracia; 12. Entremés del sacristán y el maestro de capilla; 13. Entremés del indio borracho y burlado; 14. Entremés de los deseos; 15 . Entremés de compadre Pablo o del zapato; 16. Loa de indió ${ }^{4}$.

\section{$* * *$}

El presente número monográfico de la revista América sin Nombre $(21,2016)$ que dedicamos al Teatro breve virreinal se ha concebido como un humilde aporte colectivo que trata de enriquecer los conocimientos actuales sobre este desatendido campo del arte histriónico. De los once artículos aquí reunidos, se lleva la palma una gigante de la escena barroca como es Sor Juana Inés de la Cruz, que ha concitado la atención de cuatro estudiosos. Antonio Cortijo Ocańa pone el foco en las tres loas sacramentales de la monja jerónima (para los autos de El divino Narciso, El cetro de José y El mártir del Sacramento) y en su Neptuno alegórico, textos todos ellos que se aproximan a América como tema de reflexión y análisis, donde Sor Juana expresa su orgullo de pertenecer a un Nuevo Mundo que se compara y pone en pie de igualdad con la Vieja Europa; para lograrlo, la autora a veces reivindica sin ambages el sustrato

4. De todos estos títulos, Olavarría y Ferrari solo registra un baile de Los locos (I, 127 y 130) y un sainete de Los remendones, del padre Agustín Castro (I, 26). Por otra parte, el texto de La junta de médicos difiere de sendos sainete y entremés homónimos que circulaban por España en la segunda mitad del s. XviII, de modo que tenemos tres piezas cortas distintas que se llaman igual (existe incluso impresión del Entremés nuevo la junta de médicos a nombre de Francisco Robles, en Madrid, por Gabriel Ramírez, 1763). Justo lo contrario pasa con el Sainete nuevo intitulado Fuera, cuyo texto sí coincide con el sainete del mismo título que circulaba por España a principios del s. XIX. cultural nahua de México, mientras que otras veces recurre a un mensaje cifrado, más sutil, en la estela de Atanasio Kircher y sus escritos sobre mitología e interpretación de los jeroglíficos egipcios. Susana Hernández Araico se ocupa de otro bloque de loas sorjuaninas, en concreto las siete que se dedican a festejar a la monarquía con ocasión de su onomástica: cinco de ellas se dirigen al rey Carlos II, una a la reina consorte María Luisa de Borbón y otra más a la reina madre Mariana de Austria. La estudiosa californiana se aproxima a estas loas desde una perspectiva dramatúrgica, poniendo el acento en cómo Sor Juana maneja con sabiduría la música y las sofisticadas alegorías, pero desaprovecha otras posibilidades escénicas palaciegas como serían el uso de la perspectiva, los bastidores o el telón de boca. La inclusión de las siete loas en los libros de Inundación castálida y del Segundo volumen, publicados ambos en España en 1689 y 1692, no obedece a ambiciones cortesanas de la Décima Musa, sino más bien al interés particular de los ex-virreyes (los marqueses de la Laguna), quienes brindan obsequiosos tales textos al rey como prueba del nivel cultural alcanzado en América, justo cuando ellos acaban de regresar a la metrópoli. Sara Poot Herrera pasa del palacio al corral y analiza el ejemplo singular de Los empeños de una casa, artefacto teatral que va más allá de una comedia de capa y espada cualquiera, pues nuestra monja quiso publicarla como un complejo festejo con todos sus aditamentos breves, con este resultado: Loa - Letra cantada 1 - Jornada 1 - Letra cantada 2 - Sainete 1 - Jornada 2 - Letra cantada 3 - Sainete 2 - Jornada 3 - Sarao. Diez elementos en total de los cuales siete son breves y los tres restantes conforman el cuerpo de la comedia larga. A partir de aquí surgen varios interrogantes, pues desconocemos la fecha del estreno y si se montó así en las tablas, o si bien es un producto ad hoc diseñado después por la dramaturga para ser leído tal cual en el Segundo volumen de las obras de Soror Juana Inés de la Cruz (1692). También hay certezas, pues merced a cierta información contenida en el Sainete segundo podemos conectar Los empeños con otras dos comedias de la época como son El pregonero de Dios y patriarca de los pobres, de Francisco de Acevedo, y La segunda Celestina, de Salazar y Torres, ¿en colaboración con Sor Juana? Octavio Rivera Krakowska aborda su aproximación a la autora a través de otras dos loas cortesanas o palaciegas, en concreto las dedicadas a los cumpleaños del virrey Gaspar de la Cerda y de su esposa Elvira de Toledo, condes de Galve. Son loas muy extensas para lo que es habitual en el género, que buscan la 
conjunción de la palabra con la música y el canto. A diferencia de las loas dirigidas a los reyes, que se 'echaron' in ausentia, en este caso es seguro que los homenajeados presenciaron las suyas en el palacio virreinal.

Dos artículos más dirigen su mirada hacia un dramaturgo temprano como es Fernán González de Eslava. En el primero de ellos, Blanca López de Mariscal y Paloma Vargas Montes resaltan precisamente la influencia del debate medieval (la disputatio escolástica) en sus Coloquios espirituales y sacramentales, donde los personajes suben a las tablas temas de teología, historia y filosofía con claras intenciones doctrinales y persuasivas. Por su parte, María José Rodilla León aborda esta misma obra y desvela noticias de sumo detalle y precisión (guerras, epidemias, prejuicios, prohibiciones, la Ciudad de México y sus fiestas...) que subyacen en el texto de González de Eslava; noticias que en su mayor parte han pasado desapercibidas para la crítica y que la investigadora pone al servicio de una futura edición anotada de tales Coloquios.

Sin salirnos del ámbito novohispano del siglo XVI, Beatriz Aracil Varón se ocupa del teatro evangelizador impulsado por los misioneros, sobe todo franciscanos, que se sirven con profusión de las piezas breves como instrumentos de cristianización y catequesis: tal por ejemplo los autos insertos en ciclos del calendario litúrgico como Navidad, Epifanía, Resurrección o Corpus Christi. Merecen también su atención otras formas híbridas (entre retórica y teatro) como los sermones semidramáticos y los ejemplos o neixcuitilli, voz náhuatl que viene a significar cierto 'ejemplo tomado como base de un discurso o de un sermón'; asimismo, a partir de la información consignada por fray Alonso Ponce durante su visita a las fundaciones franciscanas del virreinato, analiza el uso de la danza y el mimo en sencillas escenificaciones que los frailes impulsaban entre los indios.

Dalia Hernández Reyes salta a la Nueva España del siglo XVIII y estudia las seis loas que se exhibieron en Querétaro en 1738 al hilo de la inauguración de su famoso acueducto, las cuales se han conservado en el acostumbrado libro-relación de los fastos: Relación peregrina de la agua, del jesuita Francisco Antonio Navarrete. Los seis textos son buen ejemplo de las típicas loas de carro triunfal, donde una acción casi inexistente deja paso a una explicación pormenorizada (función ecfrástica) del aparato efímero que abraza todo el conjunto. El componente musical (música, canto y estilo recitativo) adquiere notable presencia en este tipo de piezas dieciochescas.
El virreinato del Perú queda representado por Eduardo Hopkins Rodríguez, quien examina de cerca el Entremés del Justicia y litigantes, escrito por fray Francisco del Castillo, el Ciego de la Merced. La obrita se adscribe al código satírico burlesco y se centra en las diferencias surgidas entre unos necios demandantes (litigantes) y el juez (Justicia), que trata de proteger a un inocente condenado a muerte. El investigador analiza las concomitancias que afloran entre este entremés y algunas obras de Aristófanes (Las avispas), Racine (Les Plaideurs) y, sobre todo, Françoise Gayot de Pitaval, autor de Causas célebres (1747), libro de ámbito legal y judicial que gozó de amplia fama en el siglo XVIII y que Francisco del Castillo cita entre sus versos.

El flanco del teatro escolar o de colegio queda bien cubierto por Julio Alonso Asenjo, gran experto en la materia. A él debemos el utilísimo Catálogo del Antiguo Teatro Escolar Hispánico (CATEH) que se ofrece en libre acceso en línea: <http://parnaseo. uv.es/Ars/teatresco/BaseDatos/Bases_teatro_Escolar. htm $>$. De esta base de datos se extracta la producción del teatro breve escolar virreinal hispánico que aquí nos brinda, la cual el autor va ordenando por subgéneros (diálogo, égloga, loa, encomio, decuria, entremés...), sin desatender tampoco ningún territorio (México, Perú, Chile, Filipinas...). Se añade además como apéndice la edición del Encomio sexto al Nacimiento de la Virgen, de Juan de Cigorondo, que se representó en Guadalajara (México) el año de 1596.

Se cierra este número monográfico con el artículo que Miguel Zugasti dedica al área de Filipinas, que gozaba el estatus de Capitanía General dependiente del virreinato de México. Tras pergeñar un breve recorrido del teatro hispanofilipino en el siglo XVII (en línea con Retana), acomete la edición crítica y anotada del Entremés del envidioso y el Sarao agitanado entre ocho hombres y mujeres (1677). Piezas ambas que son nuevo ejemplo del teatro escolar, ejecutado esta vez por los dominicos en Manila, en el marco de unos festejos celebrados por la reciente beatificación de tres miembros de la Orden de Predicadores: el papa Pío V, Diego de Bebaña y Margarita de Castello. Los citados entremés y sarao, junto a dos loas más y tres comedias, se publicaron en Manila en 1677 (Felipe Pardo, Sagrada fiesta, tres veces grande...), y son la primera manifestación impresa teatral de Filipinas. Ninguno de estos textos había vuelto a editarse hasta ahora.

Confiemos en que cada una de las once contribuciones a este número especial de América sin Nombre 
dedicado al Teatro breve virreinal suponga un avance -siquiera mínimo- para la crítica. Solo me resta agradecer muy sinceramente a todos los colaboradores su buen hacer y profesionalidad, así como la implicación de las colegas de la Universidad de Alicante Carmen Alemany y Eva Valero Juan (directora y secretaria de América sin Nombre), por abrir las páginas de su prestigiosa revista a este humilde proyecto.

\section{Bibliografía}

Acevedo, Francisco de. El pregonero de Dios y patriarca de los pobres. Julio Jiménez Rueda (ed.). México: Imprenta Universitaria, 1945.

Alonso Asenjo, Julio. «Dos coloquios sacramentales barrocos y un vejamen del Cartapacio curioso del P. Juan de Cigorondo. Estudio y edición». TeatrEsco, 0 (2002). [Revista electrónica: http://parnaseo.uv.es/ Ars/TEATRESCO/textos/2ColSSmo.htm].

Alonso Asenjo, Julio. "Tragedia intitulada Oçio» de Juan de Cigorondo y teatro de colegio novohispano del siglo XVI. México: El Colegio de México, 2006.

Alonso Asenjo, Julio. Teatro colegial colonial de jesuitas de México a Chile. Valencia: Universidad, 2012.

Amunátegui, Miguel Luis. Las primeras representaciones dramáticas en Chile. Santiago de Chile: Imprenta Nacional, 1888.

ANDERSON IMBERT, Enrique. Historia de la literatura hispanoamericana. México: Fondo de Cultura Económica, 1954, 2 vols. (Múltiples reediciones).

Aracil Varón, Beatriz. El teatro evangelizador. Sociedad, cultura e ideología en la Nueva España del siglo XVI. Roma: Bulzoni, 1999.

Arellano, Ignacio, y Andrés Eichmann (eds.). Entremeses, loas y coloquios de Potosí. Colección del convento de Santa Teresa. Madrid: Iberoamericana, 2005.

Argudín, Yolanda. Historia del teatro en México desde los rituales prehispánicos hasta el arte dramático de nuestros dias. México: Panorama, 1985.

Arrom, José Juan. Documentos relativos al teatro colonial de Venezuela. La Habana: Universidad, 1946.

Arrom, José Juan. El teatro de Hispanoamérica en la época colonial. La Habana: Anuario Bibliográfico Cubano, 1956. (Otra edición en México: De Andrea, 1967).

Arróniz, Othon. Teatro de evangelización en Nueva España. México: UNAM, 1979.

Azar, Héctor (coord.). Teatro mexicano. Historia y dramaturgia. México: Consejo Nacional para la Cultura y las Artes, 1992-1995. Serie de 20 volúmenes de los cuales interesan aquí los 10 primeros: 1. Festejos, ritos propiciatorios y rituales prehispánicos (Patrick
Johansson); 2. Teatro de evangelización en náhuatl (Armando Partida); 3. Autos, coloquios y entremeses del siglo Xvi (Carlos Solórzano); 4. Teatro escolar jesuita del siglo Xvi (José Quiñones Melgoza); 5. Teatro profesional jesuita del siglo XvII (Elsa Cecilia Frost); 6. Juan Ruiz de Alarcón (José Amezcua); 7. Sor Juana Inés de la Cruz (Dolores Bravo); 8. La teatralidad criolla del siglo xviI (Humberto Maldonado Macías); 9. Dramaturgia novohispana del siglo XVIII (Germán Viveros); 10. Escenificaciones neoclásicas y populares, 1797-1825 (Sergio López Mena).

Balta, Aida. Historia general del teatro en el Perú. Lima: Universidad de San Martín de Porres, 2000.

Bellini, Giuseppe. Historia de la literatura hispanoamericana. Madrid: Castalia, 1985.

Bellini, Giuseppe. Nueva historia de la literatura hispanoamericana. Madrid: Castalia, 1997.

Betancourt, Helia Gloria. Teatro franciscano de evangelización en Nueva España. Philadelphia: University of Pennsylvania, 1990.

Cabrera y Quintero, Cayetano Javier de. Obra dramática. Teatro novohispano del siglo XVIII. Claudia Parodi (ed.). México: UNAM-Dirección General de Publicaciones, 1976.

Camastra, Caterina. «El Entremés de Luisa, de los papeles incautados al maromero José Macedonio Espinosa». Boletin del Archivo General de la Nación, 6a época, 18 (2007): 34-50.

Cánepa Guzmán, Mario. El teatro en Chile: desde los indios hasta el teatro universitario. Santiago de Chile: Arancibia, 1966.

Carella, Tulio (ed.). El sainete criollo. Antología. Buenos Aires: Hachette, 1957.

Cigorondo, Juan de. Comedia a la gloriosa Magdalena. Alejandro Arteaga Martínez (ed.). México: Bonilla Artigas, 2016.

Correa, Gustavo, y Calvin Cannon. La loa en Guatemala. Contribución al estudio del teatro popular hispanoamericano. New Orleans: Middle American Research Institute-Tulane University, 1958. (Reeditado en The Native Theater in Middle America. New Orleans: Middle American Research InstituteTulane University, 1961: 1-96).

Correa, Gustavo. «Texto de un Baile de Diablos». The Native Theater in Middle America. New Orleans: Middle American Research Institute-Tulane University, 1961: 97-103.

De Miguel, Emilio, y Javier SAn José. Teatro colegial en Nueva España. Texto y contexto de "El esposo por enigma» (1646). Salamanca: Seminario de Estudios Medievales y Renacentistas, 2006. 
Díaz Vasconcelos, Luis Antonio. Apuntes para la historia de la literatura guatemalteca. I. Epocas indígena y colonial. Guatemala: Tipografía Nacional, 1942.

Diego de Ocaña, Fray. "Memoria viva» de una «tierra de olvido»: relación del viaje al Nuevo Mundo de 1599 a 1607. Beatriz Carolina Peña (ed.). Barcelona: Paso de Barca, 2013.

Eichmann, Andrés. "Nuevas notas sobre el teatro en Charcas». Ciencia y Cultura, 20 (2008): 9-37.

Espinosa Medrano, Juan de. Amar su propia muerte. Juan M. Vitulli (ed.). Madrid: Iberoamericana-CSIC, 2011.

Francisco del Castillo, Fray (el Ciego de la Merced). Obras. Rubén Vargas Ugarte (ed.). Lima: Clásicos Peruanos, 1948.

Francisco del Castillo, Fray (el Ciego de la Merced). Obra completa. César A. Debarbieri (ed.). Lima: edición del autor, 1996.

García Valdés, Celsa Carmen. "El teatro en los siglos xvI y xvII». Felipe Pedraza Jiménez (coord.). Manual de literatura hispanoamericana. I. Época virreinal. Berriozar: Cénlit, 1991: 597-681.

Gisbert, Teresa. Teatro virreinal en Bolivia. La Paz: Dirección Nacional de Informaciones de la Presidencia de la República, 1962.

GIsBerT, Teresa. Esquema de literatura virreinal en Bolivia. La Paz: Dirección Nacional de Informaciones de la Presidencia de la República, 1963. (2a edición en 1968).

Gorc, Cedomil. Historia y critica de la literatura hispanoamericana. 1. Época colonial. Barcelona: Crítica, 1988.

Gómez Haro, Eduardo. Historia del Teatro Principal de Puebla. Antiguo Coliseo o Corral de Comedias desde los primeros pasos para construirlo (1613), hasta su destrucción (1902). Puebla: Patronato del Teatro Principal, 2005.

González de Eslava, Fernán. Coloquios espirituales y sacramentales. José Rojas Garcidueñas (ed.). México: Porrúa, 1958, 2 vols. (2a edición en 1976).

González Echevarría, Roberto, y Enrique PupoWalker (eds.). The Cambridge History of Latin American Literature. Cambridge: Cambridge University Press, 1996.

González Echevarría, Roberto, y Enrique PupoWalker (eds.). Historia de la literatura hispanoamericana. I. Del descubrimiento al Modernismo. Madrid: Gredos, 2006.

HorCasitas, Fernando. El teatro nábuatl I. Épocas novohispana y moderna. México: UNAM, 1974. (2a edición en 2004).

HorCasitas, Fernando. Teatro nábuatl II. María Sten y Germán Viveros (coords.). México: UNAM, 2004.
Irving, David. «Musical politics of empire: the loa in 18th-century Manila». Early Music, 32-3 (2004): 383-402.

JimÉnez RuedA, Julio. «Textos literarios de la época colonial». Boletín del Archivo General de la Nación, 15-2 (1944): 197-367.

Juan de la Anunciación, Fray. Cuaderno de varios versos. Manuscrito 1597 de la Biblioteca Nacional de México.

Juan de la Anunciación, Fray. Poemas religiosos y profanos. Jesús Ihmoff Cabrera (ed.). Toluca: Ediciones del Gobierno del Estado de México, 1985.

Juan de la Anunciación, Fray. Coloquios. Germán Viveros (ed.). México: UNAM-Biblioteca del Estudiante Universitario, 1996.

Juana Inés de la Cruz, Sor. Obras completas. Alfonso Méndez Plancarte y Alberto G. Salceda (eds.). México: Fondo de Cultura Económica, 1951-1957, 4 vols. (Varias reediciones).

Lazo, Raimundo. Historia de la literatura hispano-americana. El periodo colonial (1492-1780). México: Porrúa, 1965.

Llamosas, Lorenzo de las. Obras. Rubén Vargas Ugarte (ed.). Lima: Clásicos Peruanos, 1950.

Llamosas, Lorenzo de las. Obra completa. César A. Debarbieri (ed.). Lima: edición del autor, 2000.

Lohmann Villena, Guillermo. El arte dramático en Lima durante el virreinato. Madrid: Escuela de Estudios Hispano-Americanos, 1945.

María y Campos, Armando de. Guia de representaciones teatrales en la Nueva España (siglos XVI al XVIII). México: Costa-Amic, 1959.

MARSILI, Ernesto. El verdadero origen del teatro argentino: la obra de los católicos. Buenos Aires: J. Lajouane, 1935.

Molinaza, José. El entremés de Llerena en el teatro hispanoamericano. Santo Domingo: Librería La Trinitaria, 2004.

Morales, Pedro de. Carta del Padre Pedro de Morales. Beatriz Mariscal Hay (ed.). México: El Colegio de México, 2000.

Olavarría y Ferrari, Enrique. Reseña histórica del teatro en México (1538-1911). México: Porrúa, 1961, 3a edición, 5 vols.

Orbea, Fernando de. La conquista de Santa Fe de Bogotá. Bogotá: Editora Guadalupe, 2002.

Ordaz, Luis. Historia del teatro argentino. Desde los origenes hasta la actualidad. Buenos Aires: Instituto Nacional de Teatro, 1999.

Orjuela, Héctor H. El teatro en la Nueva Granada. Siglos XVI-XVIII. Santafé de Bogotá: Quebecor Impreandes, 2000. 
Ortiz Bullé Goyri, Alejandro. Teatro y vida novohispana. Siete ensayos. México: Universidad Autónoma Metropolitana-Azcapotzalco, 2011.

Oviedo, José Miguel. Historia de la literatura hispanoamericana. 1. De los orígenes a la emancipación. Madrid: Alianza, 1995. (Reedición en 2012).

Partida, Armando. Teatro de evangelización en nábuatl. México: Consejo Nacional para la Cultura y las Artes, 1992.

Pascual Buxó, José. Un desconocido dramaturgo novohispano del siglo XVIII. Dos loas de Fray Lorenzo del Santísimo Sacramento. México: UNAM-Seminario de Cultura Literaria Novohispana, 2000.

Pellettieri, Osvaldo (dir.). Historia del teatro argentino en Buenos Aires. 1. El periodo de constitución (17001884). Buenos Aires: Galerna, 2005.

Peña, Margarita. Historia de la literatura mexicana. Periodo colonial. México: Alhambra Mexicana, 1989.

Peñafiel, Antonio. Monumentos del arte mexicano antiguo. Berlín: A. Asher, 1890, 3 vols.

Peralta Barnuevo, Pedro. Obras dramáticas. Irving A. Leonard (ed.). Santiago de Chile: Imprenta Universitaria, 1937.

Peralta Barnuevo, Pedro. Obras dramáticas cortas. Lima: Biblioteca Universitaria, 1964.

Pereira Salas, Eugenio. Historia del teatro en Chile, desde sus origenes hasta la muerte de Juan Casacuberta (1849). Santiago de Chile: Universidad de Chile, 1974.

Plá, Josefina. Cuatro siglos de teatro en el Paraguay. El teatro paraguayo desde sus orígenes hasta hoy, 15441988. Asunción: Universidad Nuestra Señora de la Asunción, 1990.

Poot Herrera, Sara. «Cien años de teatralidad». Raquel Chang Rodríguez (coord.). Historia de la literatura mexicana. 2. La cultura letrada en la Nueva España del siglo XVII. México: Siglo XXI, 2002: 195-243.

Prendes Guardiola, Manuel. «Elogio y sátira de la autoridad en el Perú virreinal: la Loa al corregidor Valdivieso, una pieza desconocida de la ciudad de Piura (1775)». Hipogrifo, 1-2 (2013): 95-123.

Prieto, Melquíades. «El teatro del siglo XviII». Felipe Pedraza Jiménez (coord.). Manual de literatura hispanoamericana. I. Época virreinal. Berriozar: Cénlit, 1991: 778-808.

Rela, Walter. Breve historia del teatro uruguayo. 1. De la colonia al 900. Buenos Aires: Universidad, 1966.

Retana, Wenceslao Emilio. Noticias histórico-bibliográfcas de el teatro en Filipinas desde sus orígenes hasta 1898. Madrid: Victoriano Suárez, 1910.

Reyes Posada, Carlos José. El teatro en el Nuevo Reino de Granada. Medellín: Fondo Editorial Universidad EAFIT, 2008.
Rojas Garcidueñas, José (ed.). Autos y coloquios del siglo XVI. México: UNAM-Biblioteca del Estudiante Universitario, 1939. (Reeditado en 1972 y 1989).

Rojas Garcidueñas, José, y José Juan Arrom (eds.). Tres piezas teatrales del virreinato: Tragedia del triunfo de los santos, Coloquio de los cuatro reyes de Tlaxcala, Comedia de San Francisco de Borja. México: UNAM-Dirección General de Publicaciones, 1976.

Ruiz de Alarcón, Juan. Obras completas. Agustín Millares Carlo (ed.). México-Buenos Aires: Fondo de Cultura Económica, 1957-1968, 3 vols.

Sainz Bariáin, Isabel. Poder, fasto y teatro: la "Comedia de San Francisco de Borja» (1640), de Matías de Bocanegra, en su contexto festivo. Alicante: Universidad, en prensa.

Sancho Dobles, Leonardo (ed.). Teatro breve en la Provincia de Costa Rica. Tres piezas de Joaquin de Oreamuno y Muñoz de la Trinidad. New York: IDEAIGAS, 2016.

Serrano Redonnet, Antonio E. La primera loa universitaria argentina. Buenos Aires: Universidad, 1973.

Schilling, Hildburg. Teatro profano en la Nueva España. Fines del siglo XVI a mediados del XVIII. México: Imprenta Universitaria, 1958.

Schuessler, Michael K. Artes de fundación. Teatro evangelizador y pintura mural en la Nueva España. México: UNAM, 2009.

SHELLy, Kathleen, y Grínor Rojo. «Teatro hispanoamericano colonial». Luis Ínigo Madrigal (coord.). Historia de la literatura hispanoamericana. I. Época colonial. Madrid: Cátedra, 1982: 319-365.

Silva-Santisteban, Ricardo (ed.). Antología general del teatro peruano. Lima: Pontificia Universidad Católica del Perú, 2000-2002, 5 vols.

Sten, María (coord.). El teatro franciscano en la Nueva España. Fuentes y ensayos para el estudio del teatro de evangelización en el siglo XVI. México: CONACULTAUNAM, 2000.

Sten, María, y Raquel Gutiérrez Estupiñán. No sólo ayunos y oraciones. Piezas teatrales menores en conventos de monjas (siglo XVIII). México: UNAM-Benemérita Universidad Autónoma de Puebla, 2007.

SuÁrez Radillo, Carlos Miguel. El teatro barroco hispanoamericano. México: Porrúa, 1981, 3 vols.

Tamayo Vargas, Augusto. Literatura peruana. I. Precolombina. De la conquista y del Clasicismo. Barroquismo y Neoclasicismo. Lima: Peisa, 1992.

Tolón, Edwin Teurbe, y Jorge Antonio GonzÁlez. Historia del teatro en La Habana. Santa Clara-Cuba: Universidad Central de las Villas, 1961.

Trenti Rocamora, José Luis. El teatro en la América colonial. Buenos Aires: Huarpes, 1947. 
Trenti Rocamora, José Luis. La primera pieza teatral argentina: Santa Fe, 1717. Santa Fe: Universidad Nacional del Litoral, 1949.

Trenti Rocamora, José Luis. El repertorio de la dramática colonial hispanoamericana. Buenos Aires: Alea, 1950.

VAlle y Caviedes, Juan del. Obra completa. María Leticia Cáceres, Luis Jaime Cisneros y Guillermo Lohmann Villena (eds.). Lima: Banco de Crédito del Perú, 1990.

Vargas Ugarte, Rubén. De nuestro antiguo teatro. Colección de piezas dramáticas de los siglos XVI, XVII y XVIII. Lima: Instituto de Investigaciones Históricas, 1943. (2a edición en 1974).

Vela, Eusebio. Tres comedias. Jefferson Rea Spell y Francisco Monterde (eds.). México: Imprenta Universitaria, 1948.

Velis, Carlos. Historia del teatro en El Salvador. I. De la Colonia a 1900. Chiapas: Gobierno del Estado de Chiapas-Instituto Chiapaneco de Cultura, 1993.

Viveros, Germán (ed.). Teatro dieciochesco de Nueva España. México: UNAM-Biblioteca del Estudiante Universitario, 1990.

VIVEros, Germán. «El teatro como instrumento educativo en el México del siglo XviII». Estudios de Historia Novohispana, 12 (1992): 171-180.

Viveros, Germán. Talía novohispana. Espectáculos, temas y textos teatrales dieciochescos. México: UNAM-Instituto de Investigaciones Filológicas, 1996.
Viveros, Germán. Manifestaciones teatrales en Nueva España. México: UNAM-Seminario de Cultura Literaria Novohispana, 2005.

Williams, Jerry M. El teatro del México colonial. Época misionera. New York: Peter Lang, 1992.

Zugasti, Miguel. «Edición crítica del teatro cómico breve de Lorenzo de las Llamosas: El Astrólogo (sainete) y El bureo (baile)». Ignacio Arellano y José Antonio Rodríguez Garrido (eds.). Edición y anotación de textos coloniales hispanoamericanos. Madrid: Iberoamericana, 1999: 399-439.

Zugasti, Miguel. La alegoría de América en el barroco hispánico: del arte efimero al teatro. Valencia: Pre-Textos, 2005.

Zugasti, Miguel. «Teatro recuperado en Charcas: dos loas olvidadas de fray Juan de la Torre (OSA) a la entrada del virrey Diego Morcillo en Potosí, 1716». Ignacio Arellano y José Antonio Rodríguez Garrido (eds.). El teatro en la Hispanoamérica colonial. Madrid: Iberoamericana, 2008: 295-321.

Zugasti, Miguel. «De cómo un virrey entra en México (Marqués de Villena, 1640) y de cómo los libros y relaciones de sus fastos se alojan en bibliotecas de USA». Ventana Abierta, 35-38 (2014a): 226-239.

Zugasti, Miguel. «Teatro y fiesta en honor del nuevo virrey: dos loas al Conde de la Monclova en Puebla de los Ángeles (1686) y Lima (1689)». Miguel Zugasti, Ester Abreu y M. Mirtis Caser (eds.). El teatro barroco: textos y contextos. Vitória: Universidade Federal do Espírito Santo-AITENSO, 2014b: 115-167. 